\title{
Reflection on natural kinds. Introduction to the special issue on natural kinds: language, science, and metaphysics
}

\author{
Luis Fernández Moreno ${ }^{1}$ \\ Received: 8 July 2019 / Accepted: 10 July 2019 / Published online: 15 July 2019 \\ (c) Springer Nature B.V. 2019
}

\begin{abstract}
This article is an introduction to the Synthese Special Issue, Natural Kinds: Language, Science, and Metaphysics. The issue includes new contributions to some of the main questions involved in the present philosophical debates on natural kinds and on natural kind terms. Those debates are relevant to philosophy of language, philosophy of science, and metaphysics. In philosophy of language it is highly debated what the meaning of natural kind terms is, how their reference is determined, as well as whether there are differences and similarities between the semantics of natural kind terms and that of other sorts of kind terms. In philosophy of science, natural kinds are relevant because they are the basis for scientific classifications and play an explanatory role in scientific theories; thus one aim of science is to discover natural kinds and theorize about them. Natural kinds are also relevant in metaphysics, where many questions involving natural kinds are debated and especially those concerning the sort of entities we refer to when using natural kind terms, i.e., the ontological status of natural kinds; in this regard there are different views, such as conventionalism, realism and essentialism. Another metaphysical question is what it is that characterizes the naturalness of kind divisions. The introduction sketches the antecedents of some of the present views on natural kinds and natural kind terms, and indicates some of the topics dealt with in the articles that make up the issue, which can be classified in the following groups: (1) the metaphysics and epistemology of natural kinds (2) the semantics of natural kind terms and other kind terms (3) questions on species and (4) other related issues on natural kinds. However, many of the articles cover more than just one of these topics.
\end{abstract}

Keywords Natural kind · Natural kind term · Species · Language $\cdot$ Science Metaphysics

Luis Fernández Moreno

luis.fernandez@filos.ucm.es

Extended author information available on the last page of the article 


\section{Introduction}

The background for contemporary discussions on natural kinds and natural kind terms is constituted by the theories of S. Kripke and H. Putnam put forward in the first half of the 1970s. These discussions also have more remote antecedents, especially the theories of Locke and Mill, although neither of these two authors used the expression "natural kind".

Locke's theory of natural kinds, put forward in (Locke 1690), is part of a theory of substances, since Locke alludes to the former as "material", "natural" or "bodily" substances, although by "substance" Locke mainly understands not singular substances but sorts or kinds. The entities subsumed under such substances include members of biological species_in Locke's words, “animals and vegetables" (Locke 1690: 3.11.19.) — and samples of material stuff or natural materials-in Locke's words, "inanimate bodies" (ibid.). According to Locke, natural kinds are mental entities that he calls "ideas", and more precisely one type of idea, complex abstract ideas, or nominal essences. The meaning of a substance term - a sort of general term - is the corresponding nominal essence, and an object belongs to the extension of a substance term if and only if it has the properties whose ideas constitute the nominal essence. Locke's view on natural kinds is a conventionalist one; our classification of objects into natural kinds is based on human convenience, not on the discovery of real essences. As such, his theory on the reference of natural kind terms is a (mentalist) descriptivist theory.

In (1843) J. S. Mill put forward a theory regarding the general terms that denote natural kinds, although he denominates these kinds "real Kinds" (with a capital K) or simply "Kinds". Mill characterizes Kinds, i.e., natural kinds, as classes that have "a real existence in nature" (1843, p. 4), but not all of these classes are natural kinds. The members of some classes are such that they only share very few properties, namely the ones connoted by the term that denotes the class (or perhaps also other properties derivable from them). These sorts of classes are not natural kinds; thus, the term "white" is not a natural kind according to Mill. Mill's main characterization of natural kinds is the following: "Every class which is a real Kind [...] is distinguished from all other classes by an indeterminate multitude of properties not derivable from one another" (1843, p. 126).

As for the term "natural kind" itself, in his work The Logic of Chance (1866) J. Venn discussed Mill's theory of real Kinds using the expression "natural kind", and according to Hacking Venn was the author who coined that phrase (see Hacking 1991, p. 111). The same expression was used later, among others, by Russell (1948) and Quine (1969), although both authors shared a view of natural kinds according to which they have a pre-scientific character and are to be eliminated with the progress of science.

In (Putnam 1970), Putnam considered natural kinds as important categories from a scientific point of view- "classes of things that we regard as of explanatory importance" (1970, p. 139), and he dealt with the semantics of natural kind terms in his critique of "the traditional theory of meaning", since according to Putnam that theory, represented among others by Locke, is inadequate for natural kind terms. In Putnam's characterization, according to "the traditional theory of meaning" of natural 
kind terms, a natural kind term is defined by the conjunction-or the cluster-of some terms for macroscopic properties of members of the kind in such a way that such conjunction is analytically linked with the term, and it provides necessary and sufficient conditions for kind membership. The traditional theory of meaning and reference in Putnam's sense is a sort of descriptivist theory, and this was the target of Putnam's and Kripke's criticism; however, there are nowadays more refined versions of the descriptivist theory.

Putnam (1975b), as well as Kripke (1980), maintained that the members of a natural kind possess certain intrinsic, ahistorical properties which constitute their essential properties and through which a natural kind is defined. Such properties are discoverable by scientific research, provide necessary and sufficient conditions for kind membership, and figure in laws. This view of natural kinds has been denominated the "traditional" conception of natural kinds, different from the traditional theory regarding natural kind terms in Putnam's sense. Many of the kinds posited in 'nontraditional' approaches to natural kinds differ from 'traditional' ones in many or all of the features included in the Putnam/Kripke's view on natural kinds just mentioned. One of the most significant non-traditional contemporary theories of natural kinds is Boyd's, according to which many important natural kinds are homeostatic property clusters-for references see Boyd's article in this volume. This conception is often abbreviated as the HPC view of natural kinds.

\section{The papers in the special issue}

\subsection{The metaphysics and epistemology of natural kinds}

The paper "Rethinking natural kinds, reference and truth: Towards more correspondence with reality, not less" by R. Boyd ${ }^{1}$ is wide-reaching, dealing with questions on metaphysics, semantics and epistemology. However, it has been included in the above-mentioned category to distinguish it from other papers that mainly deal with semantics. In the introductory section, Boyd mentions some of the challenges to the project of identifying a unifying metaphysics and semantics for natural kinds, as well as others to one or more of the various aspects of 'non-traditional' theories. He then asserts (in the first section) that in order to meet most of the challenges against (most) of the non-traditional views on natural kinds a new synthesis is required, resulting from a thoroughgoing naturalistic (but non-reductionist) approach to the metaphysics, semantics and epistemology of natural kinds, and indeed to metaphysics and epistemology in general; some of the components of the version of that new naturalistic synthesis are indicated in section 1. In the second section Boyd reconsiders the 'accommodationist' conception of natural kinds and reference presented in some of his previous works; he summarizes the main points of the accommodationist conception and explains new components that are necessary to address the various challenges against that view. In the third section it is argued that reference, truth and approximate truth are special

\footnotetext{
${ }^{1}$ After the paper had appeared online, Richard Boyd has noticed an unfortunate mistake: in Section 3.11 of his paper, "tritium dioxide" should be replaced in all its occurrences by "di-tritium oxide".
} 
cases of accommodation. The fourth section is devoted to the examination of accommodationist responses to several challenges against the theories that posit HPC natural kinds or other natural kinds defined by property clusters. According to Boyd, these criticisms reveal some philosophical and scientific deficiencies in the ways in which philosophers have articulated or defended the HPC view. In section 5 he proposes to remedy those deficiencies by using resources from the general accommodationist conception described in the above-mentioned sections. He then examines the challenges to non-traditional approaches to natural kinds that are focused on HPC or other clustering conceptions, and highlights the thesis that the theory of natural kinds is a component of a naturalistic, scientific epistemology. Boyd's paper contains a defense of one of the most thoroughly developed formulations of his HCP view.

In the article "No purely epistemic theory can account for the naturalness of kinds" Olivier Lemeire considers Boyd's conception, and discusses some of its features, especially Boyd's proposed criteria for natural kinds. However, his main aim is to criticize other views which, given the problems involved in a metaphysical theory of natural kinds, advocate for a definition of natural kinds only in epistemic terms - the socalled "epistemology-only theories of natural kinds". In this paper, he argues against these theories and in favor of, at least partly, metaphysical theories. He begins by proposing two desiderata for a theory of natural kinds. On the one hand, any theory that aims to account for the naturalness of kind distinctions should provide criteria that allow us to distinguish natural from conventional kinds; on the other hand, a theory of natural kinds has to provide a theoretical account of the naturalness of kinds that should explain why exactly satisfying the proposed criteria makes for natural rather than conventional categories. The author criticizes two epistemology-only theories; firstly, one example of a 'general' epistemology-only theory, proposed by Marc Ereshefsky and Thomas Reydon; secondly, an example of a 'specific' epistemology-only theory, proposed by P. D. Magnus. Lemeire argues that theories like those of the first sort fail to provide adequate criteria for natural kinds and alleges that theories of the second type cannot explain why satisfying the proposed epistemic criteria makes for natural rather than conventional kind divisions.

In her paper "Kinds behaving badly: Intentional Action and Interactive Kinds" Sophie Allen also considers Boyd's HPC conception, alongside other cluster conceptions of kinds, examining how property clusters behave when they are interactive kinds, a class of kinds suggested by Ian Hacking for which classification generates a feedback loop between the classifiers and what is classified. Allen's main thesis is that human interactive kinds should be distinguished from nonhuman ones since humans can cause classificatory feedback by bringing about changes which are anomalous with respect to the properties in the cluster associated with the kind, changes which do not occur in non-human interactive kinds. The structure of Allen's paper is the following. First, she examines Rachel Cooper's objection to Hacking, specifically Cooper's argument against his claim that a kind description is required for intentional action. In this regard she argues that even if Cooper is right that a linguistic description is not required, intentional action still essentially requires some form of classification and so Cooper's objection leaves Hacking's position prima facie intact. Second, Allen briefly considers ways in which one might characterize the ontology and semantics of interactive kinds in order to establish that her account of human interactive kinds 
does not require a particular account of semantics or ontology. Third, she investigates whether and why the fact that kind classification facilitates intentional action distinguishes human interactive kinds from the rest. She argues that the subject's awareness of the kind they are, and the awareness of others around them, can produce changes which generate a feedback loop. These changes are unique to human kinds because they arise when kind members or those around them are mistaken about the properties which they or other members instantiate, or when kind members fake the presence of properties which they do not instantiate (or pretend not to have properties which they do instantiate). Finally, she notes that her conclusion has implications for experimental design and theorizing in medical and social sciences, as well as raising questions about the extent to which feedback should alter classification in different cases.

\subsection{The semantics of natural kind terms and kind terms}

One of the most debated of Kripke's theses concerning natural kind terms is that they are rigid designators, although he only characterized rigidity explicitly for singular terms.

In his paper "Against Rigidity for Natural Kind Terms" Stephen Schwartz indicates that two responses to the difficulty of extending rigidity to natural kind terms and other general terms are rigid essentialism and rigid expressionism. After making some critical remarks on rigid essentialism, he focuses on rigid expressionism, according to which all unstructured, single word general terms are rigid; thus, common nouns and predicates including simple natural kind terms are considered proper names of the kinds (properties, universals) that they express or designate. This view has often been considered as involving the overgeneralization of rigidity according to which all natural kind terms and many other kind terms are rigid designators. However, overgeneralization does not mean that all general terms are rigid according to rigid expressionists. Rigid expressionists typically recognize a distinction between rigid general terms and non-rigid definite descriptions of kinds; thus, e.g., the color designator 'white' is rigid whereas 'the color of Antarctica' is non-rigid. Thus, accepting the overgeneralization does not involve the trivialization of the notion of rigidity for kind terms, since not every designator of a kind is rigid.

However, Schwartz also argues that the problem with rigid expressionism is that it runs together natural kind terms with non-natural kind terms in a false semantic uniformity. Since the motivation for rigid expressionism was the difficulty or impossibility of analyzing natural kind terms as rigid while non-natural kind terms are non-rigid, the only option left is rejecting the rigid/non-rigid distinction with respect to natural kind terms and other general terms. Natural kind term semantics is very different from typical non-natural kind term semantics, but this difference is not illuminated by treating them all as rigid, nor as treating natural kind terms as rigid and the non-natural kind terms as non-rigid. Schwartz argues that the Kripke/Putnam view of natural kind terms minus the claim of rigidity is correct, but a traditional descriptivist theory is appropriate for nominal kind terms; furthermore, he claims that there are simpler, clearer, more adequate ways of describing the semantics of natural kind terms than trying to stretch the notion of rigidity to fit them. 
The main aim of the paper "Tolerance, Flexibility and the Application of Kind Terms" by Genoveva Martí and Lorena Ramírez-Ludeña is to clarify a distinction in the mode of semantic operation of kind terms and to elucidate also the commitments that the different positions espouse regarding the correctness or incorrectness of judgments about the application of terms to particular cases. The relevant distinction in the semantic operation of kind terms is that between flexibility and tolerance.

On the one hand, they argue that some terms are used flexibly, in the sense that the domain of application of the term can expand or contract; in the case of flexible uses when the issue arises as to whether to classify an object or a sample or a phenomenon under the term's extension, there may be more than one open course of action compatible with the meaning of the term, more than one course of action continuous with previous usage. The use of other terms is inflexible: the extension is fixed once and for all, and any change in the domain of application is an error or a clean break with past practice, with the subsequent emergence of a new usage. Whether a term is used flexibly or inflexibly depends on all kinds of factors and accidents surrounding the history of its use.

On the other hand, there are terms whose mode of operation is tolerant, in that the intentions of speakers and other factors that bestow meaning permit the cohabitation in the speakers' community of more than one use or practice of use of the term in question, in such a way that the different uses cut up roughly the same domain of application in different ways. Those terms contrast with terms that operate in a strict way restricting severely the legitimacy of different uses.

The two pairs of distinctions-flexibly/inflexible, tolerant/strict-account in different ways for the judgments of correctness or incorrectness of applications of terms, and thus they contribute to explain the source and import of some disagreements, both in everyday life and in the legal sphere.

In his paper "A dilemma about kinds and kind terms", Ted Parent puts forward a problem concerning generic noun phrases. He considers uncontentious that some noun phrases denote kinds, like the subject-term in the following "The kind Tiger is an abstract object". Many generics, or rather generic NPs, are thought to denote kinds like the subject-terms in such sentences as "The lion has a mane" or "Dinosaurs are extinct".

Assuming the latter view, he puts forward an argument whose conclusion seems absurd. The author calls that argument "the reductio". In an example, the reductio suggests that the following claim is incorrect: 'The potato' in the sentence "The potato was cultivated in Ireland by the end of the seventeenth century" denotes a kind. For if it does, then the sentence entails that the Kind Potato, the Kind itself, was cultivated during a certain historical period. According to the author, "the reductio" entails a problem for the reference theory: what do kind terms denote in allegedly kind-denoting generics?.

Parent considers several proposals for resolving the problem, among them to reject the absurdity of the conclusion, to rule out one of the premises, or to deny that the conclusion follows from the premises. He distinguishes and examines three different versions of the latter, the non-sequitur charge: (a) the charge of "false dichotomy," (b) the charge of "unsound inference rule," and (c) the charge of "equivocation." The author argues that all of those proposals seem inadequate. Thus, the paper does not 
propose a solution to the said problem but challenges all researchers on generic noun phrases and on kind terms more generally to make proposals to solve it.

\subsection{Questions on species}

The next three papers concern the notion of (biological) species. In the article "Species are, at the same time, kinds and individuals. A causal argument based on an empirical approach to species identity", Elena Casetta and Davide Vecchi propose an answer to two questions: firstly, what follows from endorsing a general species concept concerning the identity of species taxa (i.e., their criteria of diachronic and synchronic identity)? And, secondly, what is their metaphysical status (i.e., what kind of entities are they)?

The starting point of their argument is the general species concept (in particular de Queiroz's formulation), which captures what all species concepts have in common, i.e., that species are segments of metapopulation lineages. Then the authors articulate in more detail the concept of metapopulation and gene-phene pool, which results in the following characterization of species. Species of sexually reproducing organisms are segments of metapopulation lineages whose constituents are Mendelian populations characterized by their own gene-phene pool. Given this characterization of species, the authors proceed to address the first part of their twofold metaphysical question concerning species' identity. They claim that the identity of a species is determined by the limits of the relevant metapopulation lineage segment, and the relative cohesiveness of its gene-phene pool. Thus, only by knowing the speciation process, the peculiar metapopulation dynamics, and the distinctive gene-phene pool does it become possible to recognize a particular segment of a lineage as a species and, furthermore, as that particular species.

They also argue that their empirical approach may help in settling the question of whether species taxa should be conceived as individuals or as kinds, more specifically as a peculiar sort of natural kinds defined on the basis of homeostatic property clusters (Boyd's HPC kinds), thus addressing the second part of the twofold metaphysical question mentioned above. Because of the uniqueness of the biological processes punctuating every species' life history, one possible outcome of their analysis could be that some form of ontological pluralism should be endorsed: perhaps some sexual species are individuals and others, HPC kinds. However, they exclude that outcome on the basis of a causal argument: because the biological processes at the basis of the individuality and kindness of a species are the same, what shall be concluded is that a species taxon is at the same time an individual and an HPC kind. Being an individual, it is identifiable in terms of mereological relationships. Being a kind, it is characterizable in terms of an HPC cluster, however formed and maintained.

In the paper "The Species Category as a Scientific Kind", Caleb C. Hazelwood takes as a starting point Marc Ereshefsky's project of eliminative pluralism, which is stated in two theses: (1) In light of the myriad mechanisms of speciation legitimated by scientific practice, we ought to be pluralistic realists about species concepts, and (2) as there is no unifying feature among all species concepts, we ought to doubt the existence of the species category; thus Ereshefsky advocates antirealism about that category. In his 
paper Hazelwood suggests a revised approach to realism about the species category that relies on a shift from "theory-focused to practice-centered" philosophy of science. It rests on a conception of the category as a natural kind, but this in itself is a controversial suggestion. It is controversial primarily because the standards for natural-kindhood are a subject of significant debate. The author argues that one promising strategy for being a realist about the species category is to reframe it as a natural kind after the practice turn. He does this by situating this category within an account of natural kinds proposed by Marc Ereshefsky and Thomas Reydons called "scientific kinds"—-this view is one example of a 'general' epistemology-only theory taken into consideration in Lemeire's paper mentioned above. Scientific kinds reflect ontological boundaries (i.e., they say something about the way the world is divided). Most importantly, they reflect boundaries drawn from the lab and the field, not only from the armchair. The aim of Hazelwood's paper is to situate the species category within an account of natural kinds that is largely sensitive to scientific practice-taxonomic practices, in this case. This, according to the author, will be necessary to save the species category.

In her paper "Scientific Realism with Historical Essences: The Case of Species", Marion Godman argues that the realist would do well to couple their natural kinds with essential natures in order to strengthen their epistemic and ontological credentials. These essential natures need not however be intrinsic to the kind's members; they may be historical. Her argument here will almost exclusively concern the case of species and the claim that historical essences can underpin the claims of scientific realism. She alleges that a dominant view holds that species lack essential natures, but this does not refute essentialism of species altogether as they may have historical rather than intrinsic essential natures. However, as historical essences are relational to their members, they are thought to suffer from some significant epistemic and ontological shortcomings. The view therefore seems to come at a cost for scientific realists and other ontologically committed views about species. An aim of this paper is to counter the prevailing pessimism and skepticism associated with a historical essentialist view of species. By implication, her dispute will not primarily be with intrinsic essentialism of species or only to the extent that it invokes skeptical claims against historical essences. The author argues that species have historical essences in ways that should matter for those interested in the nature of species and for those wishing to defend scientific realism in the non-fundamental sciences. For those interested in the debate about the nature of species, her aim is to provide stronger support for the idea that species have historical essential natures by demonstrating their hitherto underestimated credentials in terms of individuation and explanation. For scientific realists, the author intends to give a better sense of why a posteriori essential natures, and historical essences in particular, are suitable companions to scientific realists in biology and other "historical sciences". Godman makes this case by showing how in the paradigmatic case of species, historical essential natures do yield robust individuation and membership criteria as well as causal explanations of multiply projectable features. Moreover, the author claims that the notion of path dependency inherent in historical essences adjoins individuation with explanation. While the scope for applying similar defenses for other putative historical kinds remains a topic for future work, at least the principled resistance to such a defense has hopefully been cleared. 


\subsection{Other related issues on natural kinds}

It is often said that objects have disposition and the latter are normally analyzed by providing a meaning to disposition ascriptions like "This piece of salt is soluble". Philosophers like Carnap, Goodman, Quine, Lewis and many others have proposed analyses of such disposition ascriptions. In the paper "Natural Kinds and Dispositions: A causal analysis" Robert van Rooij and Katrin Schulz argue with Quine that the proper analysis of ascriptions of the form " $\mathrm{x}$ is disposed to $\mathrm{m}$ (when $\mathrm{C}$ )", where " $\mathrm{x}$ " denotes an object, "m" a manifestation, and " $C$ " a condition, goes like this: (i) " $\mathrm{x}$ is of natural kind k", and (ii) the generic "ks are $\mathrm{m}$ (when C)" is true. For generics, the authors propose an analysis in terms of causal powers: "ks (when $\mathrm{C}$ ) have the causal power to m". The latter, in turn, is analyzed making use of Pearl's probabilistic graphical causal models. The authors show how this natural kind analysis improves on standard conditional analyses of dispositions by avoiding the standard counterexamples, and that it gives rise to precise observable criteria under which the disposition ascription is true.

In his paper "Predication and Sortal Concepts", Max A. Freund investigates the extent to which natural kind concepts are necessary for linguistic and cognitive acts of predications. The problem is addressed within the more general setting of sortal concepts. That is, what the paper attempts to solve instead is the broader problem of whether sortal concepts in general are necessary elements in predication. A solution to this problem will apply to natural kind concepts since these concepts are also sortals related to many subjects of predication as well.

To this end, the paper first distinguishes between sortal and standard predications. Sentences like "Fido is a dog" and "Fido is white" illustrate each kind of predication, respectively; thus, predications of natural kind concepts will be sortal predications. Freund emphasizes an essential condition for every act of predication: the necessary individuation of their subjects. The predicated concept in a sortal predication clearly accounts for the required individuation. The case of standard predication, however, is different. As it is customarily viewed, it is generally thought that the only essential occurrence of a concept in a standard predication is the concept being predicated, which indeed does not individuate. Thus, from this perspective, the required individuation will have to be sought outside of the act of predication itself. As an alternative view, the author proposes to interpret standard predication as a cognitive act essentially involving sortal concepts.

Freund argues for his view, which he calls conceptual predication sortalism, on the basis of epistemic or meaning considerations. Acts of predications resulting from our interaction with the world necessarily include an endorsement of their content. This endorsement projects a state of affairs into the world (as conceived by us). The projection is nonetheless possible only if the subjects of the predications are represented as entities with specific identity conditions. This representation is precisely what only sortal concepts can provide. Acts of predication originating from combinatorial procedures of non-sortal predicates with proper names are handled differently. Sortal concepts are here needed to guarantee meaningful applications of the concepts being predicated. 
The papers in this Special Issue constitute important contributions to some of main questions involved in the present philosophical debates on natural kinds and on natural kind terms, paving the way for future work on this subject.

Acknowledgements I am grateful to Catarina Dutilh Novaes for having made this issue possible with her efficiency and conscientious work as the handling Editor-in-Chief. I'd like to thank also, of course, all of the authors for their contributions to the issue through their work and patience, and the referees who provided their invaluable expertise in assessing the papers.

\section{References}

Hacking, I. (1991). A tradition of natural kinds. Philosophical Studies, 61, 109-126.

Kripke, S. (1980). Naming and necessity. Oxford: Blackwell. (Revised and enlarged edition, first published in D. Davidson and G. Harman (eds.), Semantics of natural language, Dordrecht, Reidel, 1972).

Locke, J. (1690). An essay concerning human understanding. Oxford: Clarendon Press. (P.H. Nidditch (ed.) 1975).

Mill, J. S. (1843). A system of logic ratiocinative and inductive. Toronto: University of Toronto Press. (Reprinted in J.M. Robson (ed.) 1973).

Putnam, H. (1970). Is semantics possible?”. In H. Kiefer \& M. Munitz (Eds.), Languages, belief and metaphysics (pp. 139-152). New York: State University of New York Press. (Reprinted in H. Putnam (1975a): 139-152).

Putnam, H. (1975a). Mind, language and reality. (Philosophical Papers, Vol. 2). Cambridge: Cambridge University Press.

Putnam, H. (1975b). The meaning of 'meaning. In K. Gunderson (Ed.), Language, Mind and Knowledge (Minnesota Studies in the Philosophy of Science. Vol. 7). Minneapolis: University of Minnesota Press. (Reprinted in H. Putnam (1975a): 215-271).

Quine, V. W. (1969). Natural kinds. In V. W. Quine (Ed.), Ontological relativity and other essays (pp. 114-138). New York: Columbia University Press.

Russell, B. (1948). Human knowledge. Its scope and limits. London: George Allen \& Unwin.

Venn, J. (1866). The logic of chance: An essay on the foundations and province of the theory of probability, with especial reference to its application to moral and social science. London: MacMillan.

Publisher's Note Springer Nature remains neutral with regard to jurisdictional claims in published maps and institutional affiliations.

\section{Affiliations}

\section{Luis Fernández Moreno ${ }^{1}$}

1 Department of Logic and Theoretical Philosophy, Faculty of Philosophy, Complutense

University of Madrid, 28040 Madrid, Spain 